\title{
The effectiveness and safety of thyroxine replacement therapy for children with down syndrome and subclinical or congenital hypothyroidism-A systematic review*
}

\author{
Ashwaq H. Al-Sabban ${ }^{1 \#}$, Saleem Ahmed ${ }^{2}$, Jumana Y. Al-Aama ${ }^{1}$ \\ ${ }^{1}$ Princess Al-Jawhara Center of Excellence in Research of Hereditary Disorders (PACER.HD), Department of Genetic Medicine, \\ Faculty of Medicine, King Abdulaziz University, Jeddah, KSA; ${ }^{*}$ Corresponding Author: ahalsabban@kau.edu.sa \\ ${ }^{2}$ Department of Genetic Medicine, Faculty of Medicine, King Abdulaziz University, Jeddah, KSA
}

Received 20 May 2012; revised 18 June 2012; accepted 30 June 2012

\begin{abstract}
Introduction: Down syndrome (DS) is the most common chromosomal abnormality causing mental handicap in humans. Children with DS have significant medical problems and developmental delay which are further impaired by hypothyroidism. Those clinical features are potentially improved by using thyroxine replacement therapy. Objectives: To examine the evidence of effectiveness (motor \& mental development) and safety of thyroxine supplementation in the treatment of $\mathrm{SH}$ and $\mathrm{CH}$ in children with DS. Methods: Several medical data bases (MEDLINE, EMBASE, CINAHL, Cochrane, Clinical Trials Gov, Essential Evidence and Google) were searched until 20 October, 2011, for randomized control trials (RCTs) that had examined thyroxine's effectiveness and safety in the treatment of $\mathrm{SH}$ or $\mathrm{CH}$ in children with DS. Results: There were two high quality RCTs that examined thyroxine in the treatment of $\mathrm{CH}$ in children with DS, and no RCTs were found to have examined the effectiveness of thyroxine for $\mathrm{SH}$ in children with DS. Conclusion: The RCT which met our inclusion criteria provides the reliable evidence in recommending thyroxine for the treatment of $\mathrm{CH}$ in children with DS which is similar to the guidelines for general population. The absence of RCTs examining the treatment of $\mathrm{SH}$ in Children with DS indicates the need to conduct such trials.
\end{abstract}

\footnotetext{
"Authors' contributions: JA, AA conceived of the study; AA searched and retrieved studies. JA and AA and SA screened papers for inclusion AA extracted, categorized and interpreted data; AA drafted the manuscript. AA, JA revised the manuscript, JA edited the manuscript and all authors read and approved the final version.
}

Keywords: Down Syndrome; Children; Subclinical Hypothyroidism; Hypothyroidism; Congenital Hypothyroidism; Thyroxine

\section{BACKGROUND}

Down Syndrome (DS) is one of the most common chromosomal syndromes caused by cell division error leading to an extra copy of genetic material on all or part of the 21st chromosome. Trisomy 21 is the most common form of DS found in individuals who have 47 chromosomes in each cell. A small percentage of people with DS is mosaic in which some of the body's cells have an extra copy of chromosome 21. DS can also occur when part of chromosome 21 becomes translocated to another chromosome. Children with DS have significant medical problems which require life-long medical follow-up. It is approved by many studies that there is increased prevalence of various types of thyroid dysfunction in individuals with DS. In children with DS the prevalence of $\mathrm{SH}$ is $30 \%$. There was a single study that found the treatment with low-dose thyroxine may be beneficial for patients with TSH levels 11 - 20 [1,2].

Normal growth and development since fetal life require thyroid hormones which have a role in the fetus and the newborn infant brain development. The thyroid gland, located at the base of the neck, produces those hormones, which are mandatory to keep the metabolism working properly. Insufficient production or inadequate activity on the cellular or molecular level of thyroid hormones leads to hypothyroidism. Therefore, Thyroxine supplementation can be taken to restore normal metabolic activity by replacing the deficiency. Currently, diagnosis of congenital hypothyroidism $(\mathrm{CH})$ by neonatal screening of the general population and early treatment can prevent irreversible brain damage. Subclinical hypothyroidism $(\mathrm{SH})$ and $(\mathrm{CH})$ may damage growth, neuro- 
logical and psychological development of Children with DS $[3,4]$.

Hypothyroidism is more difficult to recognize than other thyroid disorders. Early clinical diagnosis of hypothyroidism in children with DS is especially difficult because children with DS are usually shorter in height, appear less active, have dry skin and fine hair, excess weight, constipation, bradycardia and mental impairment. These features are seen in hypothyroidism [5]. Hypothyroidism is the most common form of thyroid disorder associated with DS which may be either congenital (present at birth) or be acquired (occur at any age after birth) [6].

Asymptomatic children presenting normal T3 and T4 levels and slightly high TSH levels are called SH. That patient is considered to be mild and to represent a risk factor for evolution to overt hypothyroidism and other dysfunctions. The normal TSH levels accepted cut-off point is 4 to $5 \mathrm{mU} / \mathrm{L}$, which has been used to diagnose high concentrations of TSH $[7,8]$.

Hormone replacement therapy (levothyroxine) initiation is recommended for all children with a TSH greater than $10 \mathrm{mIU} / \mathrm{L}$, even if the free thyroxine concentration is within the normal laboratory range. However, treatment of patients with a serum TSH level between 5 and 10 $\mathrm{mIU} / \mathrm{L}$ remains controversial. The strongest arguments for levothyroxine therapy are the high risk of progression to overt hypothyroidism, the possible improvement of quality of life, and the possibility that $\mathrm{SH}$ is a cardiovascular risk factor [9-11].

This systematic review aims to determine thyroxine effectiveness and safety as a treatment of SH in children with DS (normal T3 and T4 levels and slightly high TSH levels at 5 to $20 \mathrm{mU} / \mathrm{L}$ ), and to define whether hormone replacement therapy (thyroxine treatment) can improve the motor and mental clinical features.

\section{METHODS}

Randomized controlled studies were included which compare thyroxine to placebo, to follow up or to no other intervention in the treatment of Children with DS (0 - 11 years), with the diagnosis of Hypothyroidism regardless of patients' gender or co-morbidity.

Several medical databases were searched (MEDLINE, EMBASE, CINAHL, Cochrane Central Register of Controlled Trials, and the specialized register of the Cochrane Developmental, Psychosocial and Learning Problems Group, Clinical Trials gov, Essential Evidence and the general engine Google) to 20 October, 2011.

The search words were used (Thyroxine, levothyroxine, Hormone replacement, L-thyroxine) in combination with (Children with DS, Mongolism) and (SH hypothyroidism, Asymptomatic hypothyroidism, normal T3 and
T4 levels and slightly high TSH levels, Congenital Hypothyroidism, Mild hypothyroidism), there was no language limitation. For any potential study the reference list of eligible studies and potentially relevant studies were reviewed.

Two reviewers made electronic searching; all retrieved titles and abstracts were screened independently. The studies which clearly did not meet the inclusion criteria were excluded. The full text copies of potentially relevant references were obtained and their eligibility was assessed independently by two reviewers. There was a discussion between the reviewers to place the final included studies.

The data extraction and categorization was done by two authors including the number of patients, type of comparison to Thyroxine (placebo or follow up), duration of treatment and the primary outcome. The accepted cut-off point for normal TSH levels is 4 to $5 \mathrm{mU} / \mathrm{L}$, which has been conventionally used to diagnose high concentrations of TSH [7].

The trials were assessed for methodological quality using Jadad Score (Jadad et al., 1996). In addition, evidence of allocation concealment and adequacy of addressing incomplete data were assessed [12].

\section{RESULTS}

The literature search retrieved 500 titles, 28 potential abstracts were reviewed and the full text for two studies (two different analysis on neonates enrolled in the same $\mathrm{RCT}$ ) which met the inclusion criteria were retrieved (A. S. Paul van Trotsenburg, Thomas Vulsma, et al., 2005; A. S. Paul van Trotsenburg, Bert J. Smit, Johannes H. T. M. Koelman, et al., 2006). The selected studies description is included in (Table 1) and the results of the studies are included in (Table 2).

Three studies about SH in children with DS were excluded because 2 of them were observational studies with recommendations not based on using Thyroxine as an intervention (E. Toscano, G. Pacileo, G. Limongelli, et al., 2003 and B. Tüysüz and D.B. Beker, 2001). The third study was double-blind crossover drug placebo trial but not randomized and has been done on patients with DS and $\mathrm{SH}$ who were between 2 and 51 years of age (Tirosh, E., Taub, Y. and Scher, A., 1989). There were no RCTs that met the inclusion criteria to provide reliable evidence to support recommending Thyroxine for the treatment of $\mathrm{SH}$ in DS.

There was one study comparing Thyroxine with placebo in 196 DS neonates which found modest reduction of TSH levels and development and growth improvement [13]; the other study that compared Thyroxine to placebo showed similar declines in TSH levels, but did not alter somatosensory evoked potential-measured peripheral or 
Table 1. Results of the identified studies. Meta-analysis (statistical significant) was not done due to the different outcome measurements.

\begin{tabular}{|c|c|c|c|c|c|c|c|c|c|}
\hline \multirow{2}{*}{$\begin{array}{l}\text { First author (year } \\
\text { of publication) }\end{array}$} & \multicolumn{2}{|c|}{$\begin{array}{c}\text { Analyzed } \\
\text { participants }\end{array}$} & \multirow{2}{*}{$\begin{array}{c}\text { Type of } \\
\text { hypothyroidism }\end{array}$} & \multirow{2}{*}{$\begin{array}{l}\text { Experimental } \\
\text { treatment }\end{array}$} & \multirow{2}{*}{$\begin{array}{l}\text { Control } \\
\text { treatment }\end{array}$} & \multirow{2}{*}{ Duration } & \multicolumn{2}{|c|}{ Results } & \multirow{2}{*}{$\mathbf{A} / \mathbf{E}$} \\
\hline & $\mathbf{E}$ & C & & & & & $\mathbf{E}$ & C & \\
\hline $\begin{array}{l}\text { A. S. Paul van } \\
\text { Trotsenburg et al. } 2005\end{array}$ & 90 & 91 & $\mathrm{CH}$ & $\begin{array}{l}\text { Thyroxine } \\
\text { (initial dose } \\
8 \text { per day) }\end{array}$ & Placebo & 2 years & $\begin{array}{c}\text { MD = 9.5 Age } \\
\text { delay (months) } \\
\text { MoD = 12.3 Age } \\
\text { delay (months) }\end{array}$ & $\begin{array}{l}\text { MD = 10.2 Age } \\
\text { delay (months) } \\
\text { MoD = 13.0 Age } \\
\text { delay (months) }\end{array}$ & $\begin{array}{c}\text { In both groups } \\
\text { one child had } \\
\text { suffered from } \\
\text { neonatal } \\
\text { convulsions }\end{array}$ \\
\hline $\begin{array}{c}\text { A. S. Paul van } \\
\text { Trotsenburg et al. } 2006\end{array}$ & 81 & 84 & $\mathrm{CH}$ & $\begin{array}{l}\text { Thyroxine } \\
\text { (initial dose } \\
8 \text { per day) }\end{array}$ & Placebo & 2 years & $\begin{array}{c}\mathrm{NCV}=51.0 \\
\mathrm{~m} / \text { second } \\
\mathrm{CCT}=8.83 \\
\text { milliseconds }\end{array}$ & $\begin{array}{c}\mathrm{NCV}=50.1 \\
\mathrm{~m} / \text { second } \\
\mathrm{CCT}=8.73 \\
\text { milliseconds }\end{array}$ & $\begin{array}{c}\text { Absence of } \\
\text { adverse } \\
\text { effects }\end{array}$ \\
\hline
\end{tabular}

Key: $\mathrm{E}=$ Experimental; $\mathrm{C}=$ Control; $\mathrm{CH}=$ Congenital Hypothyroidism; $\mathrm{A} / \mathrm{E}=$ Adverse Event; NR = Not Recorded; $\mathrm{MD}=\mathrm{Mental}$ Developmental; MoD = Motor Developmental; NCV = Nerve Conduction Velocity; CCT = Central Conduction Time.

Table 2. Evaluation of validity of selected studies.

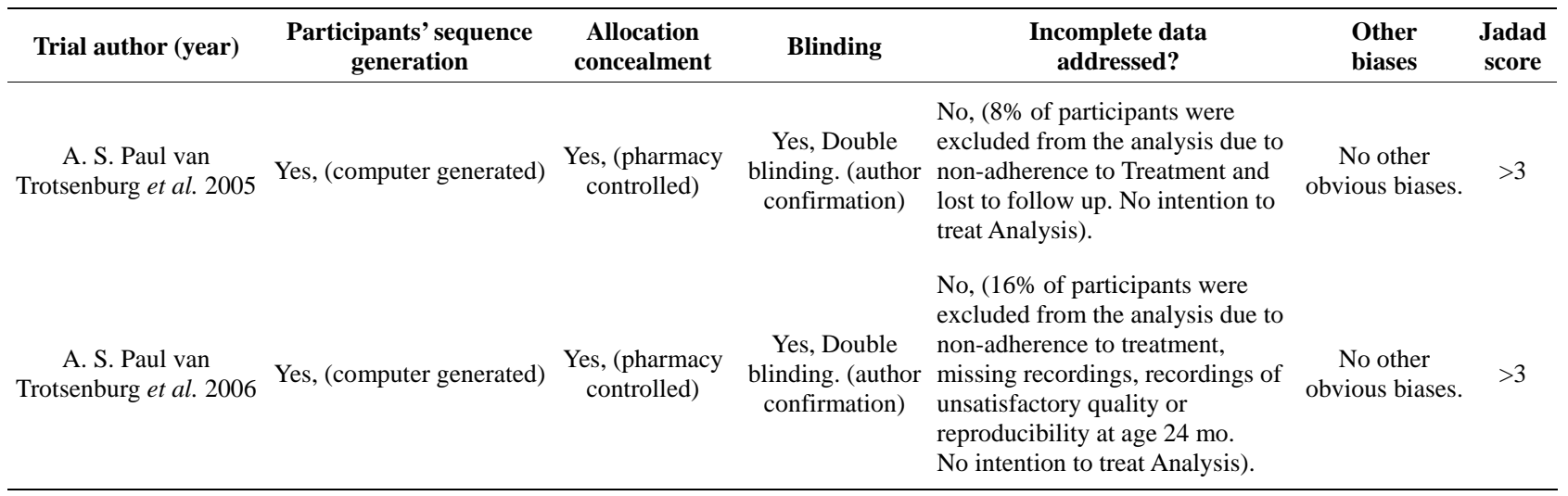

central nerve conduction significantly [14]. Meta-analysis was not done due to the different outcome measurements. The methodology of the studies and the Jadad score are described in (Table 2). Table 1 shows Thyroxine dosage and duration of use.

\section{DISCUSSION}

This systematic review discovered that there are high quality studies that examined the effectiveness and safety of using thyroxine as a treatment of $\mathrm{CH}$ in Children with DS. The two studies included in this review were of high methodological quality. How the randomization was done is mentioned by the included studies to generate participants' sequence (computer-generated randomization list). There was baseline characteristic imbalance between the experimental and the control groups in the sex, birth weight, hospital admission number and abdominal surgery in the two included studies. Allocation concealment in their methodology was controlled by pharmacy (central allocation Table 2). (A. S. Paul van Trotsenburg et al., 2005; A. S. Paul van Trotsenburg et al., 2006) [13,14].
Blinding of participants was obvious in the two included studies which compared Thyroxine to placebo because they were identical in appearance. To ensure blinding, only the endocrinologist had access to the laboratory data. However, blinding of participants and observers was done, and the blinding was assessed by telephone interview 3 - 6 months after the last study visit, in which parents were asked whether during the study they had knowledge of the kind of study medication their child received [13,14].

Withdrawals were clearly assessed by the two studies which had drop outs, the number and the reasons of participants withdrawal was stated and intention to treat analysis was used $[13,14]$. In the first study $8 \%(9 / 69)$ of the experimental group withdrew from the trial due to nonadherence to treatment and loss to follow up and were considered at the analysis of the data [12]. There were balanced withdrawal of participants from the experimental and the control groups of the two studies [13,14].

A good quality indicator in the two studies that were included in this review is that they looked at adverse events. Only one study mentioned that in both groups one child had suffered from neonatal convulsions [14] 
but it did not describe the methods used to monitor participants for events; the other study mentioned absence of adverse events. Some clinical trials reported the adverse effects of thyroxine on treated adult humans. There has been some concern that when $\mathrm{T} 4$ is given in doses that suppress serum TSH to undetectable concentrations, this might promote osteoporosis in the treated patient. In the meta-analysis of 41 cross-sectional studies by Uzzan et al. (1996), for all sites measured for BMD, suppressive thyroid hormone therapy was associated with significant bone loss in postmenopausal women [15]. In a Meta analysis of 13 cross-sectional studies by Faber and Galloe (1994), reduced serum TSH due to T4 therapy in postmenopausal women also resulted in a significant reduction in bone mass [16]. Although it is possible that those most at risk of developing osteoporosis because of T4 therapy are those whose hypothyroidism has resulted from destructive treatment of hyperthyroidism, there is a need for a large double blinded, placebo-controlled trial to assess the effect of suppressive T4 therapy on skeletal integrity $[16,17]$.

A double-blind crossover drug placebo trial found no cognitive, social and physical improvement. So, there was no evidence for the efficacy of a short-term thyroid replacement therapy for children with DS and SH [18]. In terms of the lipid and cardiovascular outcomes there is very limited clinical beneficial evidence to support the effectiveness of thyroxine in the treatment of $\mathrm{SH}$, it is important that studies involve sufficiently samples and sufficient period of participant follow up to assess participants for adverse events and assess that effectiveness of using thyroxine treatment over a time to detect infrequent events [19].

The effectiveness and safety of thyroxine for the treatment of $\mathrm{SH}$ or $\mathrm{CH}$ is might be promising for patients, because thyroxine treatment is available at low costs, adverse events absence and the evidenced observed benefits. Thyroxine as a treatment for $\mathrm{SH}$, may have some advantages including possible improvement of child quality of life, and the possibility that $\mathrm{SH}$ is a cardiovascular risk factor. The thyroxine hormone has many suggested beneficial effects including mental, neural, growth and quality of life improvement. Thyroxine treatment of young children with DS and SH may be beneficial to maximize their early development and growth [19-23].

\section{CONCLUSION}

The included studies of thyroxine effectiveness in reducing high TSH levels $>20$ were high quality with Jadad score of $>3$. The two studies that compared thyroxine to placebo provide sufficient preliminary evidence to support the use of thyroxine for children with DS and $\mathrm{CH}$. This systematic review shows that the treatment of $\mathrm{CH}$ in children with DS is similar to the general popula- tion. The treatment of $\mathrm{SH}$ in children with DS remains controversial and there are no RCTs in the field. We recommend that more high quality RCTs with long duration of follow up should be conducted using a standardized dose of thyroxine on children with DS and SH.

\section{REFERENCES}

[1] Tüysüz, B. and Beker, D.B. (2001) Thyroid dysfunction in children with Down's syndrome. Acta Pediatrica, 90, 1389-1393.

[2] Loudon, M.M., Day, R.E. and Duke, E.M. (1985) Thyroid dysfunction in Down's syndrome. Archives of Disease in Childhood, 60, 1149-1951. doi:10.1136/adc.60.12.1149

[3] Nuvarte, S. (2007) Hypothyroidism in children: Diagnosis and treatment. Journal of Pediatrics, 83, S209-S216.

[4] King, S.L., Ladda, R.L. and Kulin, H.E. (1978) Hypothyroidism in an infant with Down's syndrome. American Journal of Diseases of Children, 132, 96-97.

[5] Quinn, M.W. (1980) Down's syndrome and hypothyroidism. Irish Journal of Medical Science, 1, 19-22. doi:10.1007/BF02939103

[6] Verma, I.C. and Ghal, O.P. (1971) Hypothyroidism in children with mongolism. Indian Journal of Pediatrics, 38, 229-232. doi:10.1007/BF02823658

[7] Brabant, G., Beck-Peccoz, P., Jarzab, B., Laurberg, P., Orgiazzi, J. and Szabolcs, I. (2006) Is there a need to redefine the upper normal limit of TSH? European Journal of Endocrinology, 154, 633-637. doi:10.1530/eje.1.02136

[8] Aronson, R., Ehrlich, R.M., Bailey, J.D. and Rovet, J.F. (1990) Growth in children with congenital hypothyroidism detected by neonatal screening. Journal of Pediatrics, 116, 33-37. doi:10.1016/S0022-3476(05)81641-5

[9] Grant, D.B. (1994) Growth in early treated congenital hypothyroidism. Archives of Disease in Childhood, 70, 464-468. doi:10.1136/adc.70.6.464

[10] Glorieux, J., Dussault, J.H., Morisette, J., Desjardins, M., Letarte, J. and Guyda, H. (1985) Follow-up at ages 5 and 7 years on mental development with hypothyroidism detected by Quebec screening program. Journal of Pediatrics, 107, 913-915. doi:10.1016/S0022-3476(85)80187-6

[11] Rovet, J.F., Ehrlich, R.M. and Sorbara, D.L. (1987) Intellectual outcome in children with fetal hypothyroidism. Journal of Pediatrics, 110, 700-704. doi:10.1016/S0022-3476(87)80005-7

[12] Jadad, A.R., Moore, R.A., Carroll, D., et al. (1996) Assessing the quality of reports of randomized clinical trials: Is blinding necessary? Controlled Clinical Trials, 17, 112. doi:10.1016/0197-2456(95)00134-4

[13] van Trotsenburg, A.S.P., et al. (2006) Median nerve conduction velocity and central conduction time measured with somatosensory evoked potentials in thyroxinetreated infants with down syndrome. Pediatrics, 118, e825e832. doi:10.1542/peds.2006-0324

[14] van Trotsenburg, A.S.P., et al. (2005) The effect of thyroxine treatment started in the neonatal period on development and growth of two-year-old down syndrome chil- 
dren: A randomized clinical trial. The Journal of Clinical Endocrinology \& Metabolism, 90, 3304-3311. doi:10.1210/jc.2005-0130

[15] Uzzan, B., et al. (1996) Effects on bone mass of longterm treatment with thyroid hormones: A meta-analysis. The Journal of Clinical Endocrinology \& Metabolism, 81, 4278-4289. doi:10.1210/jc.81.12.4278

[16] Faber, J. and Galloe, A.M. (1994) Changes in bone mass during prolonged subclinical hyperthyroidism due to Lthyroxine treatment: A meta-analysis. European Journal of Endocrinology, 130, 350-356. doi:10.1530/eje.0.1300350

[17] Sawin, C.T., et al. (1994) Low serum thyrotropin concentrations as a risk factor for a trial fibrillation in older persons. The New England Journal of Medicine, 331, 12491252. doi:10.1056/NEJM199411103311901

[18] Tirosh, E., Taub, Y. and Scher, A. (1989) Short-term efficacy of thyroid hormone supplementation for patients with Down syndrome and low borderline thyroid function. American Journal of Mental Retardation, 93, 652-656.

[19] Biondi, B. and Cooper, D.S. (2008) The clinical signifi- cance of subclinical thyroid dysfunction. Endocrine Reviews, 29, 76. doi:10.1210/er.2006-0043

[20] Toscano, E., Pacileo, G., Limongelli, G., Verrengia, M., Di, M., Di, M., Salerno, M., Del Giudice, E., Caniello, B., Calabro, R. and Andria, G. (2003) Subclinical hypothyroidism and Down's syndrome; studies on myocardial structure and function. Archives of Disease in Childhood, 88, 1005-1008. doi:10.1136/adc.88.11.1005

[21] Karlsson, B., Gustafsson, J., Hedov, G., Ivarsson, S.A. and Anneren, G. (1998) Thyroid dysfunction in Down's syndrome: Relation to age and thyroid autoimmunity. Archives of Disease in Childhood, 79, 242-245. doi:10.1136/adc.79.3.242

[22] Van Trotsenburg, A.S.P., et al. (2002) Lower neonatal screening thyroxine concentrations in Down syndrome newborns. The Journal of Clinical Endocrinology \& Metabolism, 88, 1512-1515. doi:10.1210/jc.2002-021303

[23] Cetinkaya, E., Aslan, A., Vidinlisan, S. and Ocal, G. (2003) Height improvement by L-thyroxine treatment in subclinical hypothyroidism. Pediatrics International, 45, 534537. doi:10.1046/j.1442-200X.2003.01786.x 